Published in "Science of The Total Environment 672(): 634-642, 2019"

which should be cited to refer to this work.

\title{
Do invasive alien plants differ from non-invasives in dominance and nitrogen uptake in response to variation of abiotic and biotic environments under global anthropogenic change?
}

\author{
Yuan-Yuan Liu ${ }^{\text {a }}$, Yan Sun ${ }^{\mathrm{b}}$, Heinz Müller-Schärer ${ }^{\mathrm{b}}$, Rong Yan ${ }^{\mathrm{a}}$, Zhi-Xiang Zhou ${ }^{\mathrm{a}}$, \\ Yong-Jian Wang ${ }^{\mathrm{a}, *}$, Fei-Hai Yu ${ }^{\mathrm{c}}$ \\ a College of Horticulture and Forestry Sciences, Hubei Engineering Technology Research Center for Forestry Information, Huazhong Agricultural University, Wuhan 430070, China \\ ${ }^{\mathrm{b}}$ Department of Biology, University of Fribourg, Chemin du Musée 10, Fribourg 1700, Switzerland \\ ' Institute of Wetland Ecology \& Clone Ecology, Zhejiang Provincial Key Laboratory of Plant Evolutionary Ecology and Conservation, Taizhou University, Taizhou 318000, China
}

\section{H I G H L I G H T S}

- Plant invasion is the outcome of interactions of biotic and abiotic environmental factors under global anthropogenic change.

- We tested the responses of invasive and non-invasive clonal plants to variations of soil nutrient and propagule pressure. - Invasive alien clonal species had greater increase of leaf $\mathrm{N}$ than non-invasives in the variable nutrient treatment.

- Invasive alien clonal species have higher performance and advantages over noninvasives in variable environments.

\section{Keywords:}

Clonal growth

Global environmental change

Multi-species comparison

Plant invasion

Propagule pressure

Soil nutrient variability

\section{G R A P H I C A L A B S T R A C T}

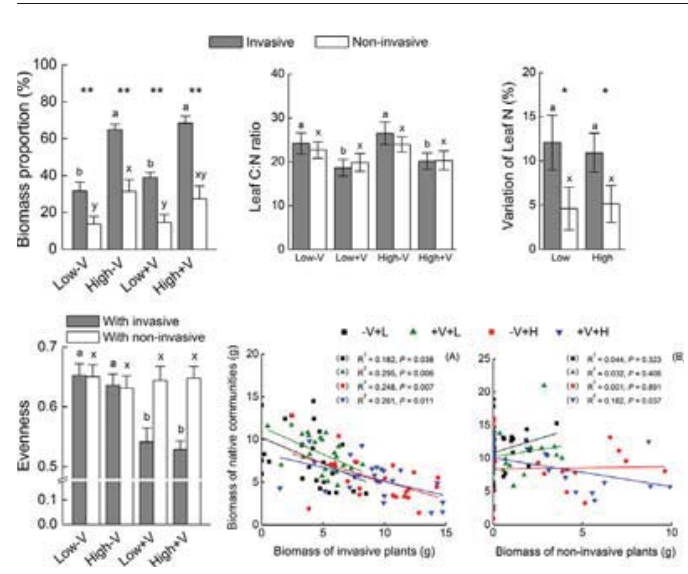

\begin{abstract}
A B S T R A C T
Plant invasion is the outcome of complicated interactions of both biotic and abiotic environments (i.e. eutrophication and human-induced propagules) under global anthropogenic change. Here, we want to know why some alien clonal plant species become invasive and others do not in the introduced range with variations of both abiotic and biotic environments under global anthropogenic change.

We selected three invasive alien and three co-occurring, non-invasive alien clonal plant species in China, and grew them under the constant or variable soil nutrient environments in a native community with low or high vegetative propagule pressure (i.e. simulating pressure of anthropogenic alien propagules).

Invasive alien species produced more biomass than non-invasives. Interestingly, invasive species benefited significantly greater from high propagule pressure than non-invasives. Biomass and evenness of native communities were greater with non-invasive than with invasive target species. Invasive plants showed a greater increase of leaf $\mathrm{N}$ and decrease of leaf $\mathrm{C}: \mathrm{N}$ ratio when subject to variable nutrients in comparison to constant nutrients than non-invasives.
\end{abstract}

\footnotetext{
* Corresponding author at: College of Horticulture and Forestry Sciences, Huazhong Agricultural University, No.1 Shizishan Street, Hongshan District, Wuhan 430070, Hubei, China. E-mail address: wangyj@mail.hzau.edu.cn (Y.-J. Wang).
} 
The negative effects of variable nutrients on evenness of native communities were significantly greater under invasive than non-invasive target species. Moreover, biomass of native communities was significantly negatively related to biomass of invasive species. Variable nutrients significantly promoted the negative biomass relationship between non-invasive species and native communities under high propagule pressure and the negative biomass-evenness relationship between invasive species and native communities.

Our study suggests that soil nutrient variability and vegetative propagule pressure influence the growth and leaf $\mathrm{C}$ and $\mathrm{N}$ uptake of alien clonal plant species in native experimental communities, especially under the high propagule pressure and nutrient variability. Invasive alien clonal species have higher performance and advantages over non-invasives. Future studies should also test the mechanisms that invasive and non-invasive or native plants differ in native communities of native or introduced ranges in the field.

(c) 2019 Elsevier B.V. All rights reserved.

\section{Introduction}

Humans activities erode geographical barriers of species dispersal into new regions around the world (Lewis and Maslin, 2015; Simberloff et al., 2013; van Kleunen et al., 2010), and negative impacts caused by global exchange of non-native plants are rapidly increasing (Hulme et al., 2008; van Kleunen et al., 2015). Plant invasion, a key process of global change, is the outcome of complicated interactions of both biotic (e.g. anthropogenic alien propagule pressure and functional traits of alien plants; Li et al., 2015; Lockwood et al., 2005; van Kleunen et al., 2011; Müller et al., 2016) and abiotic factors (e.g. resource availability and variability of environments to be invaded; Davis et al., 2000; Funk and Vitousek, 2007; Melbourne et al., 2007; Parepa et al., 2013). However, to better understand the effect of biotic and abiotic environmental variation under global anthropogenic change on invasion success, it is paramount to study invasive and non-invasive alien plant species simultaneously under common conditions.

Resource availability and variability (temporal heterogeneity) associated with altered anthropogenic regimes are common in global environmental change (Parepa et al., 2013). According to the fluctuating resource hypothesis, fluctuations or variation in resource supply via resource pulses (i.e. variability of resource availability) can decrease competitive pressure from co-occurring resident species as invasive alien plants respond more quickly to and better use resource pulses (Catford et al., 2009; Davis et al., 2000; Melbourne et al., 2007; Parepa et al., 2013). Thus, habitats with a higher variability of resources (e.g. soil nutrient and water) are more easily invaded (Catford et al., 2009; Chen et al., 2019b; Davis et al., 2000; Parepa et al., 2013; Y.J. Wang et al., 2016). Under global species exchange, the propagule pressure hypothesis (i.e. introduced propagule size, patterns, number of distinct introduction events) proposes a critical idea that an alien plant with a greater number of propagules introduced into a new location will have a higher chance to establish, spread and invade (Britton-Simmons and Abbott, 2008; Lockwood et al., 2005; Simberloff, 2009). This hypothesis has been supported by a number of studies (Colautti et al., 2006; Kempel et al., 2013; Li et al., 2015; Lockwood et al., 2005; You et al., 2016). However, impacts of propagule pressure on establishment success of alien plants may depend on other factors such as resource availability and variability of the environments to be invaded (Warren et al., 2012). In habitats with a high level of variable resources, only a few propagules of an alien plant may be sufficient to establish successfully. In contrast, in habitats with low and stable resources, a large number of propagules are needed for invasion success (You et al., 2016). So far, however, few studies have tested for interactive effects of propagule pressure and resource variability during the invasion of alien plants into native communities.

Many notorious invasive alien plants are clonal, with the capability to sustain and expand their existing populations and to establish new populations through vegetative (clonal) propagules (Chen et al., 2019a; Liu et al., 2006; Song et al., 2013; Wang et al., 2017; Yu et al., 2009). Vegetative propagule pressure may play a key role in the early invasion stages of alien clonal plants in introduced ranges ( $\mathrm{Li}$ et al., 2015; You et al., 2016). Recently, a study showed that high propagule pressure increased early establishment success of plants compared to low propagule pressure under different levels of resource availability (Kempel et al., 2013). A logical further study on whether impacts of vegetative propagule pressure on establishment success differing between invasive and non-invasive alien clonal plants and whether such impacts depend on resource variability of the habitats to be invaded is greatly needed.

We conducted a simulated experiment with three invasive alien and three non-invasive alien clonal plant species. We grew them under the constant or variable soil nutrient environments in native communities with low (one ramet) or high (six isolated ramets) vegetative propagule pressure (i.e. simulating pressure of anthropogenic alien propagules). Specifically, we addressed the following questions: (1) Do vegetative propagule pressure and nutrient variability affect growth performance and leaf $\mathrm{C}$ and $\mathrm{N}$ of invasive and non-invasive alien plants in native communities? (2) Does the relationship between biomass of alien species and biomass or evenness of natural communities differ between invasive and non-invasive species?

\section{Materials and methods}

\subsection{The species}

We chose three invasive alien and three co-occurring naturalized non-invasive alien clonal plant species in China as the target species (Table A1). All six species are capable of clonal growth by producing plagiotropic stems (stolons) that can root and form leaves at their nodes (He, 2012; Ma, 2014).

To construct native grassland plant communities, we used six common perennial herbaceous species in grasslands native to China, i.e. Glechoma longituba (Nakai) Kupr. (Lamiaceae), Dichondra micrantha Urb. (Convolvulaceae), Zoysia japonica Steud. (Poaceae), Cynodon dactylon (L.) Pers. (Poaceae), Hydrocotyle sibthorpioides Lam. (Araliaceae) and Paspalum orbiculare Forst. (Poaceae). We chose these six native species because they co-occur with the target species (He, 2012; Liu et al., 2017).

Ramets of both alien and native plant species were collected from Hubei and Guangdong Province in southern China. For each species, $>100$ ramets were collected from three locations at least $500 \mathrm{~m}$ apart to increase the likelihood that ramets came from different genets (i.e. genotypes). All ramets were collected in the spring of 2014 and cultivated vegetatively in a plastic-covered growth house at Huazhong Agricultural University in Wuhan, Hubei Province, China. In August 2015, we selected 112 ramets for each alien species (totally 672 ramets for 
all six alien species) and 192 ramets for each native species (totally 1152 ramets for all six native species). Each ramet had three leaves and some roots.

\subsection{Experimental design}

The experiment was conducted in a clear plastic-covered growth house of the forestry experimental center of Huazhong Agricultural University in Wuhan, Hubei Province, China. We planted native plant communities each consisting of one ramet of each of the six native species, in total six species with regular hexagonal distribution (i.e. equal distance between neighboring ramets was $8.5 \mathrm{~cm}$ ) in a square pot (24 cm long $\times 24 \mathrm{~cm}$ wide $\times 18 \mathrm{~cm}$ high) filled with a $1: 2(\mathrm{v} / \mathrm{v})$ even mixture of sand and yellow-brown soil collected from Shizishan Mountain in Wuhan, Hubei Province, China. We planted one or six ramets of the alien target species in the center of each pot with hexagonal design (ramet distance in six ramets treatment was $2.0 \mathrm{~cm}$ ) (Fig. A1).

Each of the three invasive and the three non-invasive alien target species were subjected to two levels of nutrient variability (constant vs. variable) crossed with two levels of vegetative propagule pressure (low vs. high). We planted only one ramet of the alien target species in the center of the pot for the low propagule pressure treatment and six for the high propagule pressure treatment. For the constant nutrient treatment, we added evenly $0.45 \mathrm{~g}$ water-soluble fertilizer $(20 \% \mathrm{~N}, 20 \%$ $\mathrm{P}_{2} \mathrm{O}_{5}, 20 \% \mathrm{~K}_{2} \mathrm{O}$, Peters Professional, Scotts, Geldermalsen, The Netherlands) per pot per week (i.e. total $4.5 \mathrm{~g}$ for 10 weeks); for the variable nutrient treatment, we added the same total amount of the fertilizer (i.e. $4.5 \mathrm{~g}$ ) to the pot, but distributed them unevenly (i.e. added 0.15 , $0.60,0.30,0.15,0.85,0.55,0.35,0.75,0.65$ and $0.15 \mathrm{~g}$ fertilizer per pot from the 1st to the 10th week). The large pulse started five weeks after experimental setup, at a time when all plants were growing vigorously (Parepa et al., 2013). There were eight replicates in each treatment and 192 pots in total (6 alien target species $\times 2$ propagule pressure treatments $\times 2$ nutrient treatments $\times 8$ replicates).

We planted all ramets on 16 August 2015 and started adding nutrients two weeks later. No ramet died during this time. Plants were regularly watered throughout the experiment. A broad-spectrum insecticide (The Dow Chemical Company, Midland, United States) were applied against diseases and insect herbivory once every two weeks. The pots were positioned randomly at the start of the experiment and rearranged every 10 days to avoid potential effects of micro-environments.

During the experiment, light intensity in the growth house was 85\% of that outside. The mean temperature and mean relative humidity in the growth house were $25.7{ }^{\circ} \mathrm{C}$ and $70.5 \%$, respectively (Amprobe TR300, Amprobe, Everett, WA, USA). The experiment was started on 31 August 2015 and ended on 9 November 2015, lasting for 70 days (10 weeks).

\subsection{Measurements and calculations}

At the end of the experiment, the aboveground and belowground parts of all plants of each species were harvested separately, dried at $80{ }^{\circ} \mathrm{C}$ for at least $72 \mathrm{~h}$ and weighed.

Invasion success of alien plants is commonly evaluated by measurement of the proportion of community biomass it represented (Parepa et al., 2013). Therefore, we calculated biomass proportion of target species as the proportion of total biomass of the alien target plant species to total biomass of the whole community (alien target species plus native plant species) of each pot. Biomass of a native community was the sum of the biomass of the six native species in a pot. We calculated evenness $(J)$ of a native community as $J=$ $-\Sigma P_{i} \ln \left(P_{i}\right) / \ln (S)$, where $i=1,2 \ldots S, P_{i}$ is the biomass of native species $i$ in a pot divided by the sum of biomass of all native species in the pot, and $S$ is the number of native species in the native community (pot) (Li et al., 2015; Yu et al., 2009).

For each alien species, dried leaves were ground into powder to measure carbon (C) and $\mathrm{N}$ concentrations. After combustion, $\mathrm{C}$ and $\mathrm{N}$ concentrations were measured by a Thermo-Finnigan elemental analyzer (Thermo Scientific, Waltham, MA, USA) in the College of Resources and Environment, Southwest University, China. We calculated $\mathrm{N}$ and C:N ratio, which is an important indicator of element utilization and uptake. For each alien species, variation of leaf $\mathrm{N}$ between variable and constant nutrient was calculated as $\mathrm{V}=\left(N_{+}-N_{-\mathrm{V}}\right) / N_{-\mathrm{V}}$, where $+\mathrm{V}$ is variable nutrient and $-\mathrm{V}$ is constant nutrient treatment. Positive or negative values indicate facilitation or stress of plant trait (i.e. leaf $\mathrm{N}$ ) under the variable nutrient compared to constant nutrient treatment, respectively, and zero indicates neutral.

\subsection{Statistical analysis}

We used linear mixed models to analyze data (total biomass, aboveground mass and belowground mass, biomass proportion of the alien target species, and total biomass, aboveground mass and belowground mass and evenness of the native plant communities) with the package "nlme" in R (Pinheiro et al., 2015). In these models, we included invasion status in China (invasive alien vs. non-invasive alien), nutrient variability (without vs. with, i.e. constant vs. variable nutrient), vegetative propagule pressure (low vs. high) and their interactions as fixed factors. We also used Log-likelihood-ratio to evaluate the significance differences of the fixed factors, and Chi squared $\left(\chi^{2}\right)$ distribution of the calculated log-likelihood ratios was exhibited in above linear mixed models (Zuur et al., 2009). We also used ANOVAs if there were significant differences in leaf C: $\mathrm{N}$ ratio and variation of $\mathrm{N}$ for invasive and non-invasive species between constant and variable nutrient and between low and high propagule pressure treatments.

Table 1

Results of mixed linear models for effects of invasion status (invasive alien vs. non-invasive alien), nutrient variability (without vs. with) and vegetative propagule pressure (low vs. high) on biomass and biomass proportion of alien species.

\begin{tabular}{|c|c|c|c|c|c|c|c|c|c|}
\hline \multirow[t]{2}{*}{ Effect } & \multirow[t]{2}{*}{ df } & \multicolumn{2}{|c|}{ Biomass } & \multicolumn{2}{|c|}{ Aboveground mass } & \multicolumn{2}{|c|}{ Belowground mass } & \multicolumn{2}{|c|}{ Biomass proportion } \\
\hline & & $x^{2}$ & $P$ & $\chi^{2}$ & $P$ & $\chi^{2}$ & $P$ & $\chi^{2}$ & $P$ \\
\hline \multicolumn{10}{|l|}{ Fixed factor } \\
\hline Status $(S)$ & 1 & 10.77 & 0.001 & 7.90 & 0.005 & 3.79 & 0.052 & 9.72 & 0.002 \\
\hline Nutrient variability (V) & 1 & 0.02 & 0.889 & 0.014 & 0.905 & 0.04 & 0.848 & 0.61 & 0.436 \\
\hline Propagule pressure $(\mathrm{P})$ & 1 & 26.14 & $<0.001$ & 25.89 & $<0.001$ & 26.88 & $<0.001$ & 18.05 & $<0.001$ \\
\hline $\mathrm{S} \times \mathrm{V}$ & 1 & 0.25 & 0.618 & 0.07 & 0.793 & 0.904 & 0.342 & 0.02 & 0.897 \\
\hline $\mathrm{S} \times \mathrm{P}$ & 1 & 65.91 & $<0.001$ & 49.99 & $<0.001$ & 50.14 & $<0.001$ & 65.70 & $<0.001$ \\
\hline $\mathrm{V} \times \mathrm{P}$ & 1 & 0.99 & 0.319 & 1.03 & 0.311 & 0.91 & 0.340 & 1.83 & 0.177 \\
\hline $\mathrm{S} \times \mathrm{V} \times \mathrm{P}$ & 1 & $<0.01$ & 0.950 & 0.07 & 0.797 & 0.30 & 0.584 & 0.49 & 0.483 \\
\hline Random factor & & $\mathrm{SD}$ & & $\mathrm{SD}$ & & SD & & SD & \\
\hline Species within family & & 0.723 & & 0.689 & & 0.567 & & 0.056 & \\
\hline Residual & & 1.647 & & 0.929 & & 1.044 & & 0.085 & \\
\hline
\end{tabular}

Values are in bold when $P<0.05$ and in italic when $0.05<P<0.1$. 

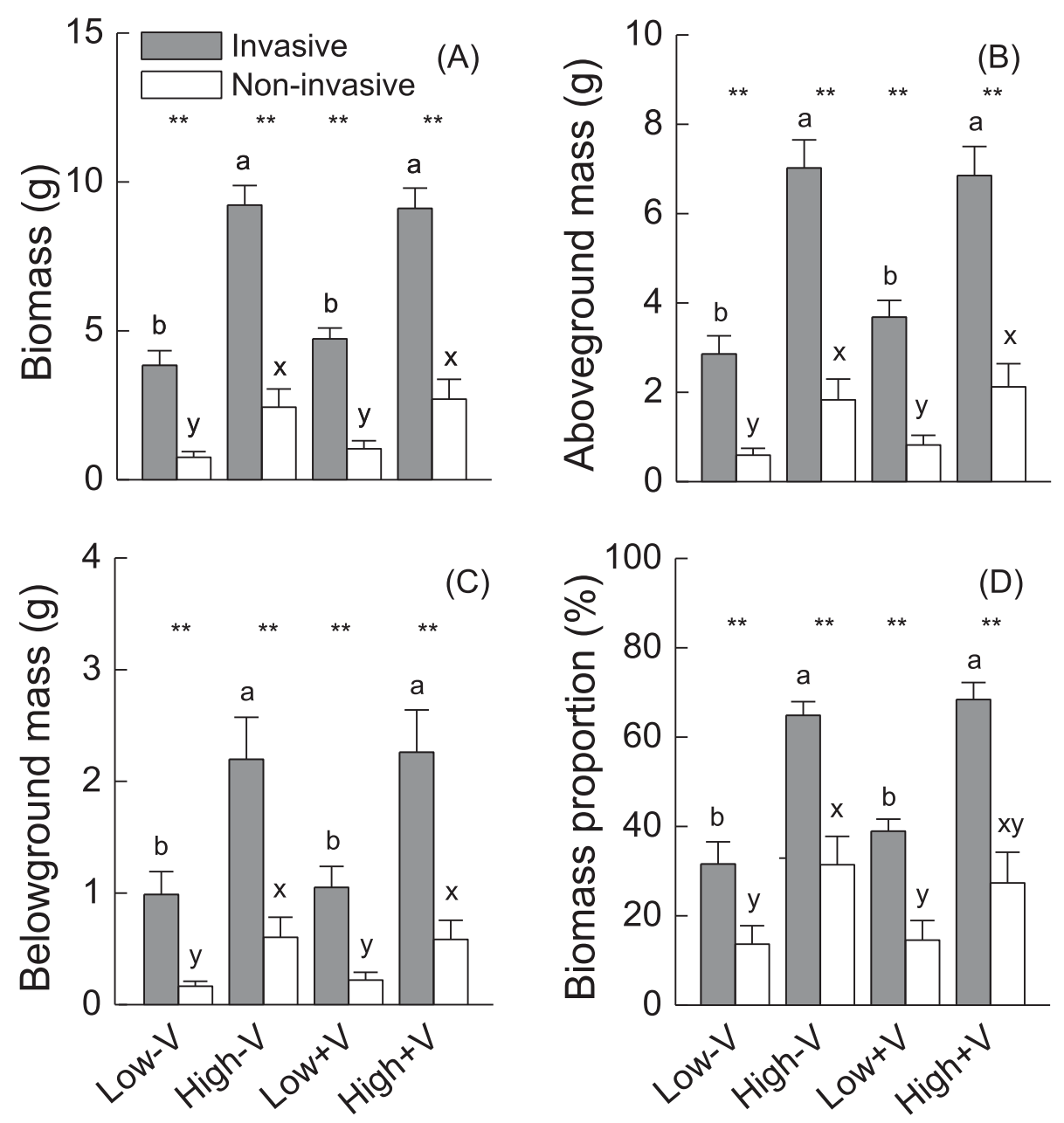

Fig. 1. Total biomass (A), aboveground mass (B), belowground mass (C) and biomass proportion (D) of invasive and non-invasive alien clonal plants without or with variable nutrient ( $-\mathrm{V}$ or $+\mathrm{V}$ ) and with low or high vegetative propagule pressure (low or high). Mean \pm SE are given. Letters at ends of bars show which means differed between nutrient and pressure treatments; symbols at ends of bars show which means differed between species origin (paired $t$-tests): no symbol, $P \geq 0.05 ;{ }^{*} P<0.05 ;{ }^{* *} P<0.05$.

Linear regression models were used to analyze the relationships between biomass or evenness of native communities and biomass of alien target species. We used model-II regression, since the data of each pot was not independent. To assess the influence of two nutrient variability and two vegetative propagule pressure treatments on the above relationships, we ran the models under all four treatments divided by nutrient variability and propagule pressure for invasive and non-invasive target species independently $(n=24)$. We also ran the results of the model with the data in the constant and variable nutrient $(\mathrm{n}=48)$, or in the high and low propagule pressure $(\mathrm{n}=48)$, with the full data set $(\mathrm{n}=$ 96) (Table A2; Fig. A3), as the effect of alien biomass on biomass of native communities was mainly in line with full factorial analysis. We used ANCOVA to compare the difference between slopes of the linear regression in the high and low propagule pressure. All analyses were conducted using R software (version 3.0.2; R Development Core Team, 2010).

\section{Results}

\subsection{Effects on the growth and leaf $C, N$ of alien plants}

Total biomass, aboveground mass, belowground mass and biomass proportion were larger in the invasive alien than in the noninvasive alien species, and in the high than in the low vegetative propagule pressure treatment in our experiment (Table 1; Fig. 1). Moreover, the effects of propagule pressure were stronger in the invasive than in the non-invasive species, as indicated by a significant interaction of status $\times$ propagule pressure (Table 1 ; Fig. 1 ). Leaf $\mathrm{C}: \mathrm{N}$ ratios of invasive plants were significantly lower in the variable than in the constant nutrient treatment across both propagule pressure (Fig. 2A). However, the effect was not significant in noninvasive plants (Fig. 2A). Variation of leaf $\mathrm{N}$ was significantly higher in invasive than in non-invasive plants, which indicated a greater increase of leaf $\mathrm{N}$ in invasive when subject to the variable nutrient treatment (Fig. 2B).

\subsection{Effects on the growth and evenness of native communities}

Evenness values of the native communities were significantly lower when the alien target species were invasive than when they were non-invasive, and decreased with increasing vegetative propagule pressure (Table 2; Fig. 3). Total biomass, aboveground mass, belowground mass exhibited similar patterns to evenness (Table 2; Fig. A2). Interestingly, evenness was significantly lower in the variable than in the constant nutrient treatment, and the negative effect was stronger with the invasive than with noninvasive alien target species $(P<0.001$ for status $\times$ nutrient variability, Table 2; Fig. A2). 

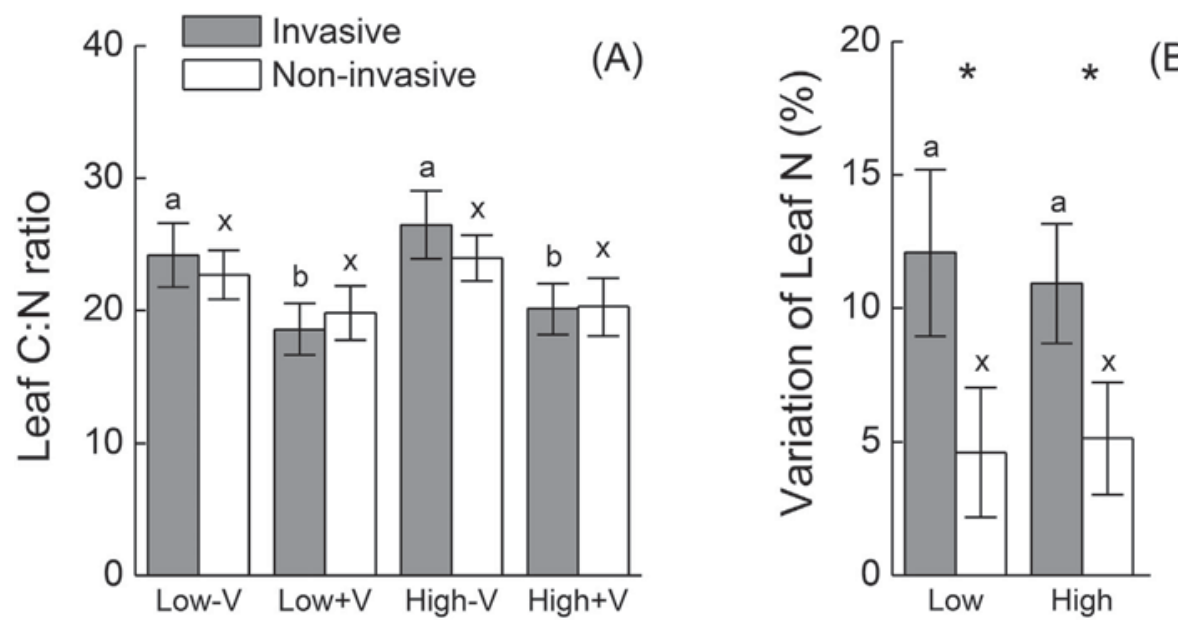

(B)

Fig. 2. Leaf C: $N$ ratio between invasive and non-invasive alien clonal plants without or with variable nutrient $(-\mathrm{V}$ or $+\mathrm{V})$ and with low or high vegetative propagule pressure (low or high) $(A)$, and their variation of leaf $N(B)$ with low or high propagule pressure. Mean \pm SE are given. Letters at ends of bars show which means differed between nutrient and pressure treatments; symbols at ends of bars show which means differed between species origin (paired $t$-tests): no symbol, $P \geq 0.05 ;{ }^{*} P<0.05$.

3.3. Relationships between biomass of alien plants and biomass or evenness of native communities

Biomass of invasive plant species were significantly negatively related with biomass of experimentally assembled native communities in the four treatments of nutrient variability and propagule pressure (Fig. 4A; Fig. A3, $P<0.05$ ). The biomass relationship between non-invasive plants and native communities were only significant under the variable nutrient and high propagule pressure $(+\mathrm{V}+\mathrm{H})$ (Fig. 4B, $P<0.05)$. The negative biomass relationship between invasive plants and native communities was steeper in the low than in the high propagule pressure within the variable nutrient (slopes of the linear regression in the high and low propagule treatments were $\mathrm{x}$ and $\mathrm{y}$; ANCOVA, $F=3.452, P=$ 0.047 ), suggesting that under the variable nutrient increasing unit biomass of invasive plants has a larger negative effect on biomass of native communities when the propagule pressure was lower (Fig. 4A).

Moreover, biomass of invasive plants was significantly negatively related with evenness of the native communities under the variable nutrient compared with the constant nutrient (Fig. 5A, $P<0.05$ ). The relationships were not significant between non-invasive and native communities either under the constant or variable nutrient treatments (Fig. 5B, $P>0.05$ ).

\section{Discussion}

4.1. Effects of propagule pressure on the growth performance of both invasive and non-invasive alien clonal plants

Our results suggest that the growth and biomass proportion of alien species were significantly greater under the high than under the low vegetative propagule pressure of the target species. These results are in line with the previous studies in which propagule number/availability exhibited positive effects on the assemblage probability of alien species by lessening risks from environmental stochasticity (Colautti et al., 2006; Lockwood et al., 2005; Simberloff, 2009). Propagule availability was positively correlated with establishment success of alien plants, as more propagules arrived in a new habitat, the probability of successful spread and invasion increased (Lockwood et al., 2005; Simberloff, 2009; You et al., 2016). Furthermore, the positive effects of propagule pressure on the growth of alien species were more pronounced in the invasive than in the non-invasive alien species. The importance of propagule pressure and invasiveness traits might be confounded, because species with traits promoting establishment might produce larger numbers and size, regardless of seeds or vegetative propagules (Colautti et al., 2006; Kempel et al., 2013; Uya et al., 2018). Hence, alien species with the capacity of taking advantage of vegetative propagules to survive and establish in

Table 2

Results of mixed linear models for effects of invasion status (invasive alien vs. non-invasive alien), nutrient variability (without vs. with) and vegetative propagule pressure (low vs. high) on biomass and evenness of the native communities.

\begin{tabular}{|c|c|c|c|c|c|c|c|c|c|}
\hline \multirow[t]{2}{*}{ Effect } & \multirow[t]{2}{*}{ df } & \multicolumn{2}{|c|}{ Biomass } & \multicolumn{2}{|c|}{ Aboveground mass } & \multicolumn{2}{|c|}{ Belowground mass } & \multicolumn{2}{|c|}{ Evenness } \\
\hline & & $\chi^{2}$ & $P$ & $\chi^{2}$ & $P$ & $\chi^{2}$ & $P$ & $x^{2}$ & $P$ \\
\hline \multicolumn{10}{|l|}{ Fixed factor } \\
\hline Status (S) & 1 & 5.57 & 0.018 & 5.96 & 0.015 & 2.82 & 0.093 & 4.22 & 0.040 \\
\hline Nutrient variability (V) & 1 & 0.01 & 0.911 & 0.01 & 0.928 & 1.13 & 0.288 & 13.39 & $<\mathbf{0 . 0 0 1}$ \\
\hline Propagule pressure $(\mathrm{P})$ & 1 & 35.26 & $<0.001$ & 35.40 & $<0.001$ & 17.19 & $<0.001$ & 2.88 & 0.090 \\
\hline $\mathrm{S} \times \mathrm{V}$ & 1 & 0.51 & 0.476 & 0.41 & 0.523 & 0.81 & 0.368 & 23.85 & $<\mathbf{0 . 0 0 1}$ \\
\hline $\mathrm{S} \times \mathrm{P}$ & 1 & 0.58 & 0.448 & 0.89 & 0.345 & $<0.01$ & 0.961 & 0.10 & 0.753 \\
\hline $\mathrm{V} \times \mathrm{P}$ & 1 & 0.02 & 0.889 & 0.01 & 0.920 & 0.69 & 0.407 & 0.34 & 0.563 \\
\hline $\mathrm{S} \times \mathrm{V} \times \mathrm{P}$ & 1 & 1.48 & 0.224 & 0.97 & 0.325 & 3.53 & 0.060 & 0.60 & 0.438 \\
\hline Random factor & & \multicolumn{2}{|l|}{ SD } & \multicolumn{2}{|l|}{ SD } & \multicolumn{2}{|l|}{ SD } & \multicolumn{2}{|l|}{ SD } \\
\hline Species within family & & \multicolumn{2}{|l|}{0.809} & \multicolumn{2}{|l|}{0.699} & \multicolumn{2}{|l|}{0.084} & \multicolumn{2}{|l|}{0.017} \\
\hline Residual & & \multicolumn{2}{|l|}{2.354} & \multicolumn{2}{|l|}{1.958} & \multicolumn{2}{|l|}{0.573} & \multicolumn{2}{|l|}{0.091} \\
\hline
\end{tabular}

Values are in bold when $P<0.05$ and in italic when $0.05<P<0.1$. 


\section{With invasive With non-invasive}

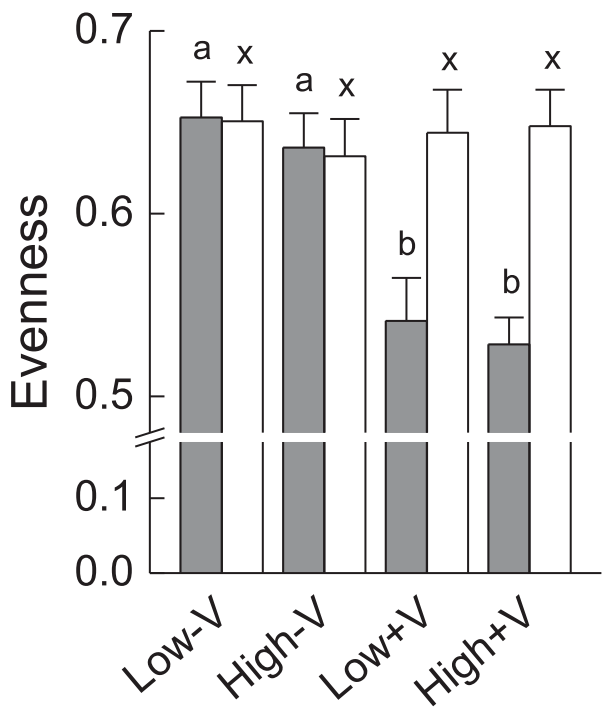

Fig. 3. Evenness of the native communities grown with invasive and non-invasive alien plants without or with variable nutrient $(-\mathrm{V}$ or $+\mathrm{V})$ and with low or high vegetative propagule pressure (low or high). Mean \pm SE are given. Letters at ends of bars show which means differed between nutrient and pressure treatments.

benign environmental conditions (Richards et al., 2006), should be more likely to become invasive than those species that are not capable of high performance (Britton-Simmons and Abbott, 2008; Simberloff, 2009). Thus, with high propagule supply invasive alien clonal plants accumulated more biomass and occupied more resource space and availability to establish in comparison to noninvasive alien clonal plants. Furthermore the invasives were probably superior competitors in native communities. This was in line with our results that the growth and evenness of experimentally assembled native communities significantly decreased with increasing vegetative propagule pressure of target species, especially more with invasive species than with non-invasive species. Meanwhile, negative biomass linear relationship between invasive species and experimentally assembled native communities also indicated the competitive superior of invasive species.

\subsection{Effects of soil nutrient variability on growth performance and leaf $C, N$ acquisition in alien clonal plants}

Invasive alien plants showed a greater increase of leaf $\mathrm{N}$ but decrease of leaf C: $\mathrm{N}$ ratio when subject to variable nutrient in comparison to noninvasives. These indicated invasive plants had higher $\mathrm{N}$ acquisition efficiency in soil variable nutrient as they were able to exploit increased soil nutrient pools during their establishment better than native plants (Parepa et al., 2013; Liu and van Kleunen, 2017). Furthermore, mixed linear model and linear regression results both showed that biomass and evenness of native communities was significantly lower under the variable nutrient than those under the constant nutrient. Under the variable nutrient, these parameters decreased with increasing biomass of invasive target plants, and the negative effect was more pronounced with the invasive than with the noninvasive target plants. The results were in line with recent multispecies research showing that invasion status of an alien plant species was partly determined by the way they dealt with or responded to soil nutrient availability (Dostál et al., 2013; Keser et al., 2014; Song et al., 2013) or determined by their variability (Chen et al., 2019b; Funk and Vitousek, 2007; Parepa et al., 2013). Therefore many alien clonal plants may become invasive elsewhere through a strong vigorous growth or clonal propagation response to resource heterogeneity or variability (Chen et al., 2019a; Dong, 1996; Keser et al., 2014, 2015; Liu et al., 2006; N. Wang et al., 2016; Y.J. Wang et al., 2016). Our results were also consistent with the previous findings, which demonstrated that high resource variability can increase dominance and promote invasion of Japanese knotweed, a clonal plant, in native communities (Parepa et al., 2013), and can facilitate the growth and dominance of alien clonal plants and decrease the evenness of communities ( Li et al., 2015; N. Wang et al., 2016; Y.J. Wang et al., 2016).

Interestingly, under the variable nutrient and low propagule pressure, increasing of unit biomass of invasive plants had a larger negative effect on biomass of assembled native communities. As invasive alien clonal species might have higher resource uptake ability in the stage of high nutrient availability via clonal traits (e.g. root-foraging behavior or clonal integration) (Wang et al., 2017; Chen et al., 2019b), it can
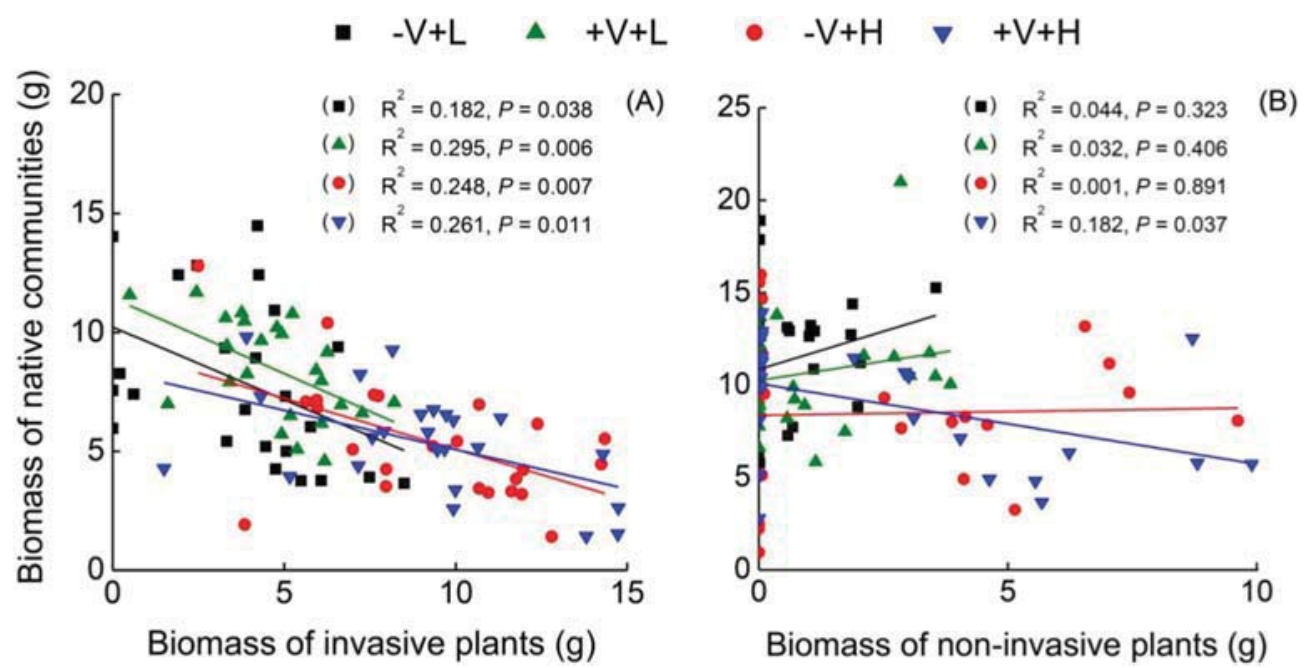

Fig. 4. Relationships of biomass of invasive (A) or non-invasive alien plants (B) with biomass of the native communities in four treatments that without or with variable nutrient $(-\mathrm{V}$ or $+\mathrm{V})$ and with low or high vegetative propagule pressure ( $\mathrm{L}$ or $\mathrm{H})(\mathrm{n}=24$ for invasive and non-invasive, respectively). 

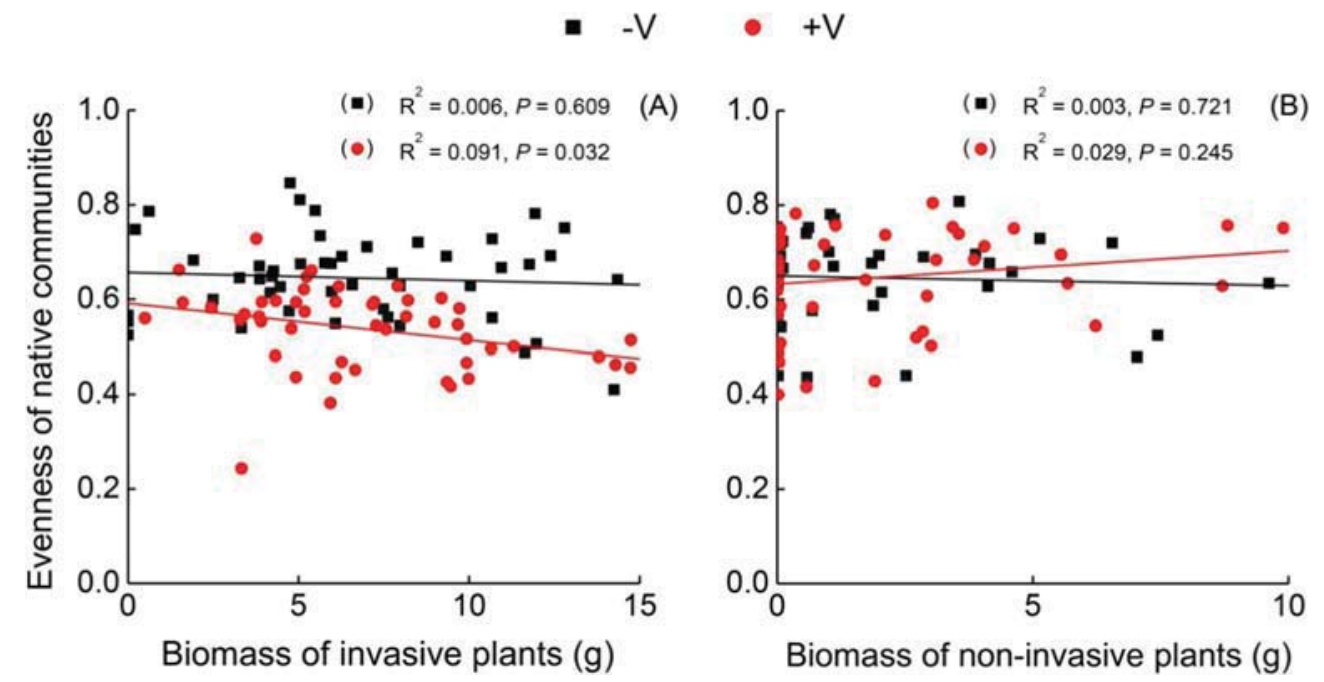

Fig. 5. Relationships of biomass of invasive (A) or non-invasive alien plants (B) with evenness of the native communities without or with variable nutrient $(-V$ or $+V$ ) ( $n=48$ for invasive and non-invasive, respectively).

respond quicker to nutrient pulses and capitalize on periods of high resource availability (Parepa et al., 2013). As results of integrative clonal growth, invasive clonal plants could possibly enable buffering of any differences in nutrient supply among ramets in resource heterogeneity and might further enhance the development of the whole plant (N. Wang et al., 2016; Y.J. Wang et al., 2016). Therefore, the capacity of a strong clonal response in a temporal interval of nutrient conditions might be positively correlated to species success or invasiveness. It was documented that variability of soil nutrient availability may play a role in species invasiveness as well. Interactions between nutrient variability and propagule pressure also leads a significantly negative biomass relationship between non-invasive plants and native communities. Under the variable nutrient and high propagule pressure, some of alien naturalized species might become invasive in future. When invasive plants invaded native communities, high propagule pressure and variable nutrient might result in the enhanced integrative growth of the whole invasive plant population, and suppress the growth of most native species. Integrative interactions of high nutrient variability and propagule pressure can increase competition intensity among individual plants, and promote the competitive growth of invasive species, thereby decrease the evenness of communities via nonuniform suppression on native species. As a result, the role of propagule pressure and nutrient variability in the invasion success of the whole invasive population in native communities seems to be pronouncedly significant.

The negative relationship between the growth of invasive species and the evenness of native communities was more obvious when supplied with variable nutrient than with constant nutrient. This coincided with the difference in root growth and biomass accumulation for six native species, respectively, in response to a variation in the mean nutrient level. During the pulse, native Glechoma longituba with a large root mass has the advantage to take immediate advantage of the temporary surplus of nutrients. Thus, the pulse markedly increased biomass and dominance of native G. longituba, but deceased those of other native species with the presence of invasive species. Our results coincided with the finding that high resource variability can decrease the evenness of communities (Li et al., 2015). Resource heterogeneity might dramatically increase competition intensity for the resource among native plants, consequently greatly influenced size hierarchy of evenness of communities (Lamb and Cahill, 2008; Li et al., 2015; Yu et al., 2009). Due to species-specific responses to the multiple pulses, variable nutrient then might result in the decrease in evenness of biomass distribution of native communities under the high nutrient variability.

\section{Conclusion}

Our study indicated that soil nutrient variability and vegetative propagule pressure influenced the growth and leaf $\mathrm{C}$ and $\mathrm{N}$ uptake of alien clonal plant species in native experimental communities, especially under the high propagule pressure and nutrient variability. In consistent with our expectations, propagule pressure, nutrient variability and their interactions can alter the relationships between the performance of invasive or non-invasive alien plants and the growth or evenness of native communities. The high environmental adaptation and competitive ability of invasive clonal plants promote their growth and establishment in native communities. It highlights the interactions of both biotic and abiotic environmental factors under global change play an important role during invasion processes of alien plants. In addition, other biotic and abiotic environmental factors such as the forms of $\mathrm{N}$ or other essential element, soil micro-organisms, enemies, as well as temperature also should be assessed during plant invasion in new introduced habitats. Therefore, future studies should also test the mechanisms that invasive alien and non-invasive alien or native plant species differ in native communities of native or introduced ranges in special ecosystems, such as wetlands and forests.

\section{Acknowledgements}

We thank Prof. Bo Zheng for English revision. We thank Ai-Ming Cai, Lie Xu, Ping Zhang, Jiang-Hua Liu, and Xiao-Hui Yong for their help during the course of the experiment. This research was funded by the National Natural Science Foundation of China (No. 31770449, 31570413, 31270465), Key Technologies R\&D Program (2017YFC0505605), and Fundamental Research Funds for the Central Universities (2662016PY064).

\section{Author contributions}

Y.J.W. and Z.X.Z. designed the experiment and did the statistical analysis, R.Y. performed the experiment, Y.Y.L. and Y.J.W. wrote the first draft of the manuscript, H.M.-S., Y.S. and F.H·Y contributed substantially to the revisions. 


\section{Appendix A}

Table A1

The six co-existing invasive and non-invasive alien species used in the experiment.

\begin{tabular}{|c|c|c|c|c|c|}
\hline Species & Family & Status & Invasive rank $\mathrm{k}^{\mathrm{a}}$ & Native range & Typical habitats \\
\hline Alternanthera philoxeroides (Mart.) Griseb & Amaranthaceae & Invasive & 1 & South America & Wetlands, canals, nearby fields \\
\hline Hydrocotyle vulgaris L. & Araliaceae & Invasive & 2 & Europe, North America & Wetlands, other moist habitats \\
\hline Sphagneticola trilobata (L.) Pruski. & Asteraceae & Invasive & 2 & North and South America & $\begin{array}{l}\text { Moist grasslands, edges of canals, } \\
\text { roadsides, garden }\end{array}$ \\
\hline Euphorbia maculata Raf. & Euphorbiaceae & Non-invasive & 7 & North America & $\begin{array}{l}\text { Moist grasslands, roadsides, } \\
\text { farmland, other moist habitats }\end{array}$ \\
\hline Kyllinga brevifolia Rottb. & Cyperaceae & Non-invasive & 7 & Tropical areas of the world & Nearby fields, grasslands, Roadsides \\
\hline Oxalis corymbosa DC. & Oxalidaceae & Non-invasive & 5 & South America & $\begin{array}{l}\text { Low altitude mountain, paddy field, } \\
\text { roadsides }\end{array}$ \\
\hline
\end{tabular}

Status and habitat information are based on the Flora of China (www.efloras.org) and other references He (2012) and Ma (2014).

a Invasive rank: "1" means highest and "7" means lowest for alien plants in Ma (2014).

Table A2

Linear regressions between biomass of alien target species and biomass of the native communities without (constant) or with variable nutrient $(-\mathrm{V}$ or $+\mathrm{V}$ ), and with the low or high vegetative propagule pressure of the alien target species, respectively ( $\mathrm{n}=48$ for invasive and non-invasive in each model).

\begin{tabular}{|c|c|c|c|c|c|c|}
\hline \multirow[t]{2}{*}{ Target species } & \multirow[t]{2}{*}{ Conditions } & \multicolumn{2}{|c|}{ Coefficient } & \multirow[t]{2}{*}{$\mathrm{R}^{2}$} & \multirow[t]{2}{*}{$F$} & \multirow[t]{2}{*}{ Sig. } \\
\hline & & $\mathrm{a}$ & $\mathrm{b}$ & & & \\
\hline Invasive & Constant nutrient & 9.752 & -0.475 & 0.326 & 22.222 & $<0.001$ \\
\hline Invasive & Variable nutrient & 9.982 & -0.444 & 0.345 & 24.251 & $<0.001$ \\
\hline Non-invasive & Constant nutrient & 10.186 & -0.135 & 0.006 & 0.278 & 0.601 \\
\hline Non-invasive & Variable nutrient & 10.571 & -0.389 & 0.092 & 4.632 & 0.037 \\
\hline Invasive & Low propagule pressure & 10.575 & -0.564 & 0.183 & 10.286 & 0.002 \\
\hline Invasive & High propagule pressure & 8.047 & -0.289 & 0.159 & 8.697 & 0.005 \\
\hline Non-invasive & Low propagule pressure & 10.654 & 0.471 & 0.027 & 1.256 & 0.268 \\
\hline Non-invasive & High propagule pressure & 9.233 & -0.213 & 0.032 & 1.528 & 0.223 \\
\hline
\end{tabular}
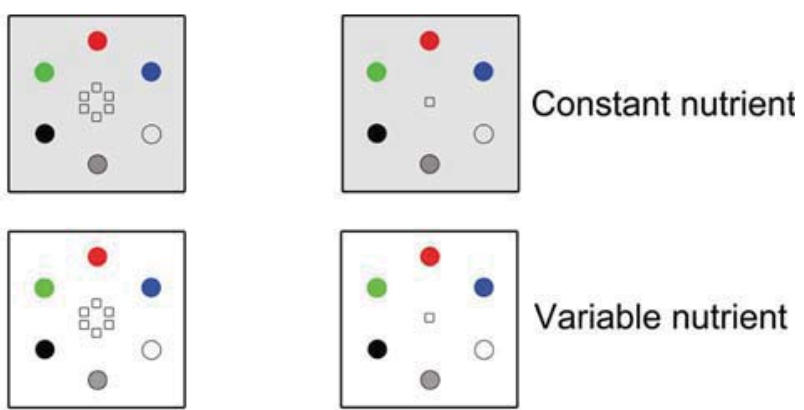

High propagule pressure Low propagule pressure

Fig. A1. Experimental design. Three invasive and three co-existing non-invasive alien clonal species, and six co-existing native clonal species were used in the experiment. The experiment used a factorial design with two treatments of invasive status of target species (invasive alien vs. non-invasive alien), two treatments of nutrient variability (constant and variable) and two treatments of vegetative propagule pressure (low and high pressure, i.e. one ramet and six isolated ramets of target species). One or six hollow square in the center of the container represents the low or the high vegetative propagule pressure of target species. Six circles with different colors are different co-existing native species and are planted surround with a regularly hexagonal design, which represents a native community in our experiment.

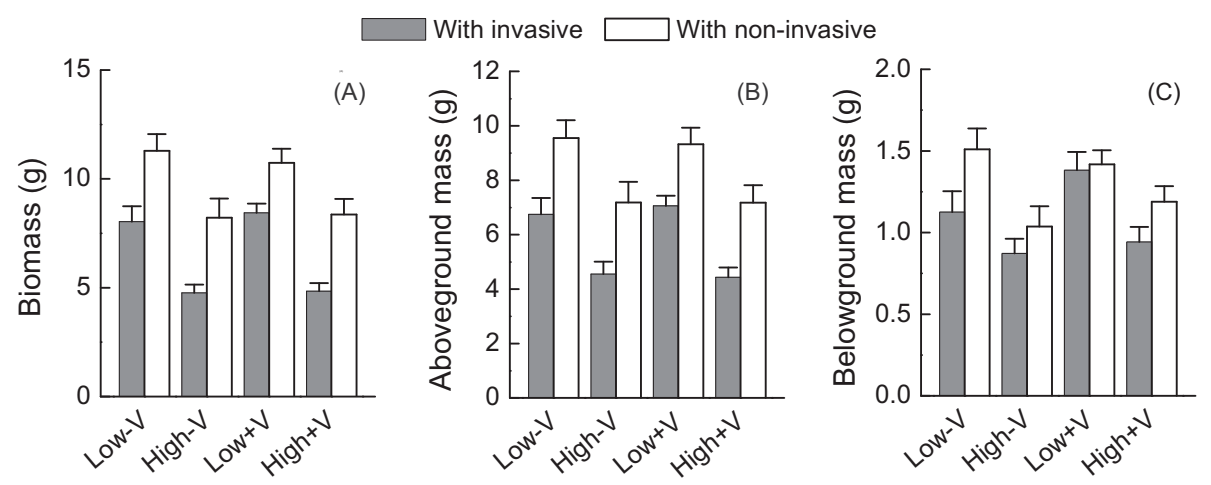

Fig. A2. Total biomass (A), aboveground mass (B) and belowground mass (C) of the native communities grown with invasive and non-invasive alien plants without or with variable nutrition $(-\mathrm{V}$ or $+\mathrm{V})$ and with low or high vegetative propagule pressure (low or high). Mean $\pm \mathrm{SE}$ are given. 

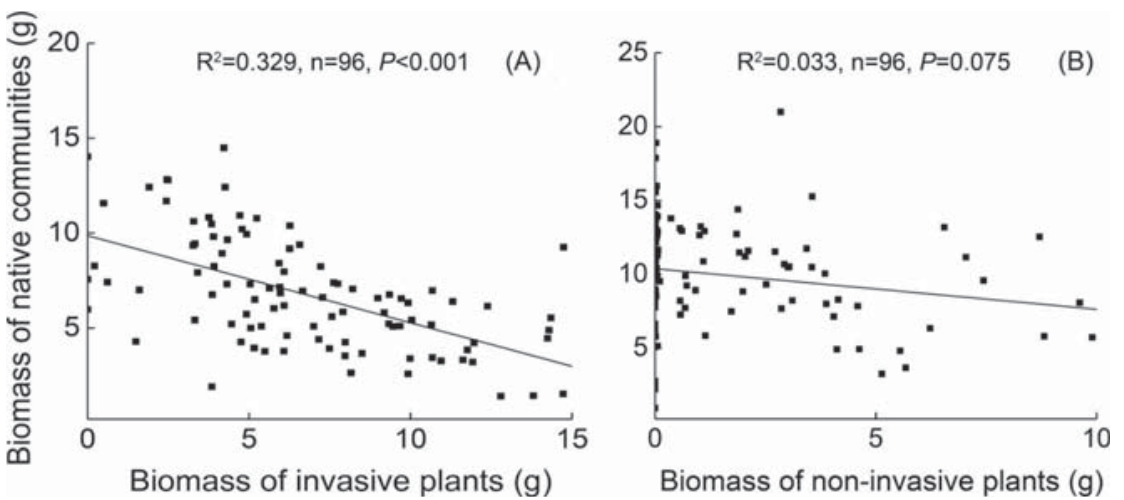

Fig. A3. Relationships of biomass of invasive (A) or non-invasive alien plants (B) with biomass of the native communities. The subset of cases where the alien plants were grown without or with variable nutrient $(-\mathrm{V}$ or $+\mathrm{V})$ and with low or high vegetative propagule pressure (low or high) ( $\mathrm{n}=96$ for invasive and non-invasive respectively).

\section{References}

Britton-Simmons, K.H., Abbott, K.C., 2008. Short- and long-term effects of disturbance and propagule pressure on a biological invasion. J. Ecol. 96, 68-77.

Catford, J.A., Jansson, R., Nilsson, C., 2009. Reducing redundancy in invasion ecology by integrating hypotheses into a single theoretical framework. Divers. Distrib. 15, 22-40.

Chen, D., Ali, A., Yong, X.H., Lin, C.G., Niu, X.H., Cai, A.M., Dong, B.C., Zhou, Z.X., Wang, Y.J. Yu, F.H., 2019a. A multi-species comparison of selective placement patterns of ramets in invasive alien and native clonal plants to light, soil nutrient and water heterogeneity. Sci. Total Environ. 657, 1568-1577.

Chen, D., Xiong, H., Lin, C.G., He, W., Zhang, Z.W., Wang, H., Wang, Y.J., 2019b. Clonal integration benefits invasive alien plants under water variability in a native community. J. Plant Ecol. https://doi.org/10.1093/jpe/rty050.

Colautti, R.I., Grigorovich, I.A., MacIsaac, H.J., 2006. Propagule pressure: a null model for biological invasions. Biol. Invasions 8, 1023-1037.

Davis, M.A., Grime, J.P., Thompson, K., 2000. Fluctuating resources in plant communities: a general theory of invasibility. J. Ecol. 88, 528-534.

Dong, M., 1996. Clonal growth in plants in relation to resource heterogeneity: foraging behavior. Acta Bot. Sin. 38, 828-835 (in Chinese with English Abstract).

Dostál, P., Müllerová, J., Pyšek, P., Pergl, J., Klinerová, T., 2013. The impact of an invasive plant changes over time. Ecol. Lett. 16, 1277-1284.

Funk, J.L., Vitousek, P.M., 2007. Resource-use efficiency and plant invasion in low-resource systems. Nature 446, 1079-1081.

He, J.Q., 2012. Exotic Plants in China. Shanghai Scientific and Technical Publishes, Shanghai.

Hulme, P.E., Bacher, S., Kenis, M., Klotz, S., Kühn, I., Minchin, D., Nentwig, W., Olenin, S. Panov, V., Pergl, J., Pyšek, P., Roques, A., Sol, D., Solarz, W., Vilà, M., 2008. Grasping at the routes of biological invasions: a framework for integrating pathways into policy. J. Appl. Ecol. 45, 403-414

Kempel, A., Chrobock, T., Fischer, M., Rohr, R.P., van Kleunen, M., 2013. Determinants of plant establishment success in a multispecies introduction experiment with native and alien species. Proc. Natl. Acad. Sci. 110, 12727-12732.

Keser, L.H., Dawson, W., Song, Y.B., Yu, F.H., Fischer, M., Dong, M., van Kleunen, M., 2014. Invasive clonal plant species have a greater root-foraging plasticity than non-invasive ones. Oecologia 174, 1055-1064.

Keser, LH, Visser, EJW, Dawson, W., Song Y B, Yu, F.H., Fischer, M. Dong M, van Kleunen, M., 2015. Herbaceous plants species invading natural areas tend to have stronger adaptive root foraging than other naturalized species. Front. Plant Sci. 6, 273.

Lamb, E.G., Cahill, J.F., 2008. When competition does not matter: grassland diversity and community composition. Am. Nat. 171, 777-787.

Lewis, S.L Maslin, M.A., 2015. Defining the Anthropocene. Nature 171, 171-180.

Li, H.L., Wang, Y.Y., Zhang, Q., Wang, P., Zhang, M.X., Yu, F.H., 2015. Vegetative propagule pressure and water depth affect biomass and evenness of submerged macrophyte communities. PLoS One 10, e0142586.

Liu, Y., van Kleunen, M., 2017. Responses of common and rare aliens and natives to nutrient availability and fluctuations. J. Ecol. 105, 1111-1122.

Liu, J., Dong, M., Miao, S.L., Li, Z.Y., Song, M.H., Wang, R.Q., 2006. Invasive alien plants in China: role of clonality and geographical origin. Biol. Invasions 8, 1461-1470.

Liu, J.H., Yong, X.H., Han, Q., Ali, A., Wang, Y.J., 2017. Response of plant functional traits to species origin and adaptive reproduction in weeds. Plant Biosyst. 151, 323-330.

Lockwood, J.L., Cassey, P., Blackburn, T., 2005. The role of propagule pressure in explaining species invasions. Trends Ecol. Evol. 20, 223-228.

Ma, J.S., 2014. The Survey Report on Chinese Alien Invasive Plants, Part I and II. (949 pages). High Education Press, Beijing, China.

Melbourne, B.A., Cornell, H.V., Davies, K.F., Dugaw, C.J., Elmendorf, S., Freestone, A.L. et al 2007. Invasion in a heterogeneous world: resistance, coexistence or hostile takeover? Ecol. Lett. 10, 77-94.

Müller, G., Horstmeyer, L., Rönneburg, T., van Kleunen, M., Dawson, W., 2016. Alien and native plant establishment in grassland communities is more strongly affected by disturbance than above- and below-ground enemies. J. Ecol. 104, 1233-1242.
Parepa, M., Fischer, M., Bossdorf, O., 2013. Environmental variability promotes plant invasion. Nat. Commun. 4, 1604

Pinheiro, J. Bates, D, DebRoy, S, Sarkar, D, R Core Team, 2015. nlme: linear and nonlinear mixed effects models. R package version 3.1-119. http://CRAN.R-project.org/package $=$ nlme

R Development Core Team, 2010. R: A Language and Environment for Statistical Computing. R Foundation for Statistical Computing, Vienna, Austria Available at. http://www. R-project.org.

Richards, C.L., Bossdorf, O., Muth, N.Z., Gurevitch, J., Pigliucci, M., 2006. Jack of all trades, master of some? On the role of phenotypic plasticity in plant invasions. Ecol. Lett. 9, 981-993.

Simberloff, D., 2009. The role of propagule pressure in biological invasions. Annu. Rev. Ecol. Evol. Syst. 40, 81-102.

Simberloff, D., Martin, J., Genovesi, P., Maris, V., Wardle, D.A., Aronson, J., Courchamp, F., Galil, B., García-Berthou, E., Pascal, M., Pyšek, P., Sousa, R., Tabacchi, E., Vilà, M., 2013. Impacts of biological invasions: what's what and the way forward. Trends Ecol. Evol. 28, 58-66.

Song, Y.B., Yu, F.H., Keser, L.H., Dawson, W., Fischer, M., Dong, M., van Kleunen, M., 2013. United we stand, divided we fall: a meta-analysis of experiments on clonal integration and its relationship to invasiveness. Oecologia 171, 317-327.

Uya, M., Bulleri, F., Gribben, P.E., 2018. Propagules are not all equal: traits of vegetative fragments and disturbance regulate invasion success. Ecology 99, 957-965.

van Kleunen, M., Weber, E., Fischer, M., 2010. A meta-analysis of trait differences between invasive and non-invasive plant species. Ecol. Lett. 13, 235-245.

van Kleunen, M., Schlaepfer, D.R., Glaettli, M., Fischer, M., 2011. Preadapted for invasiveness: do species traits or their plastic response to shading differ between invasive and non-invasive plant species in their native range? J. Biogeogr. 38, 1294-1304.

van Kleunen, M., Dawson, W., Essl, F., Pergl, J., Winter, M., Weber, E., Kreft, H., Weigelt, P., Kartesz, J., Nishino, M., Antonova, L.A., Barcelona, J.F., Cabezas, F.J., Cárdenas, D., Cárdenas-Toro, J. Castaño, N., Chacón, E Chatelain, C Ebel, A.L., Figueiredo, E. Fuentes, N., Groom, Q.J., Henderson, L., Inderjit, Kupriyanov, A., Masciadri, S., Meerman, J., Morozova, O., Moser, D., Nickrent, D.L., Patzelt, A., Pelser, P.B., Baptiste, M.P., Poopath, M., Schulze, M., Seebens, H., Shu, W.S., Thomas, J., Velayos, M., Wieringa, J.J., Pyšek, P., 2015. Global exchange and accumulation of non-native plants. Nature 525, 100-103.

Wang, N., Li, W., Zhou, B., Yan, X., 2016. Invasiveness, clonal form and geographical origin of invasive clonal plant species in China. Biodivers. Sci. 24, 12-19 (in Chinese with English Abstract).

Wang, Y.J., Bai, Y.F., Zeng, S.O., Yao, B., Wang, W., Luo, F.L., 2016. Heterogeneous water supply affects growth and benefits of clonal integration between co-existing invasive and native Hydrocotyle species. Sci. Rep. 6, 29420.

Wang, Y.J., Müller-Schärer, H., van Kleunen, M., Cai, A.M., Zhang, P., Yan, R., Yu, F.H., 2017. Invasive alien plants benefit more from clonal integration in heterogeneous environments than natives. New Phytol. 216, 1072-1078.

Warren, R.J., Bahn, V., Bradford, M.A., 2012. The interaction between propagule pressure, habitat suitability and density-dependent reproduction in species invasion. Oikos $121,874-881$.

You, W.H., Han, C.M., Fang L.X., Du, D.L., 2016. Propagule pressure, habitat conditions and clonal integration influence the establishment and growth of an invasive clonal plant, Alternanthera philoxeroides. Front. Plant Sci. 7, 568.

Yu, F.H., Wang, N., Alpert, P., He, W.M., Dong, M., 2009. Physiological integration in an introduced, invasive plant increases its spread into experimental communities and modifies their structure. Am. J. Bot. 96, 1983-1989.

Zuur, A.F., Ieno, E.N., Walker, N.J., Saveliev, A.A., Smith, G.M., 2009. Mixed Effects Models and Extensions in Ecology with R. Springer, New York. 